\title{
Carbon Nanotube@MnO_@Polypyrrole Composites: Chemical Synthesis, Characterization and Application in Supercapacitors
}

\author{
Ariadne Helena Pequeno de Oliveira ${ }^{a, b}$, Marcio Luis Ferreira Nascimento ${ }^{b}$, Helinando Pequeno de Oliveira ${ }^{a *}$ \\ ${ }^{a}$ Institute of Materials Science, Federal University of Sao Francisco Valley-UNIVASF, 48902-300, \\ Juazeiro, BA, Brazil \\ ${ }^{b}$ Department of Chemical Engineering, Polytechnic School, Federal University of Bahia - UFBA, \\ 40210-630 Salvador, BA, Brazil
}

Received: May 3, 2016; Accepted: July 25, 2016

\begin{abstract}
Core/shell structures of carbon-based materials/ metal oxide have been considered as potential candidates for electrochemical devices due to their improved pseudocapacitance/electrical double layer capacitance and high conductivity/ superior surface area. The development of multiple coreshell structures of MWCNT@ $\mathrm{MnO}_{2} @$ PPy was analyzed as a standard procedure for mass production of supercapacitor electrodes. The relative concentration of carbon nanotubes in the composite was varied to optimize the double layer capacitance contribution in overall response of device. Resulting structures presented capacitance in order of $272.7 \mathrm{Fg}^{-1}$ and reasonable cycling performance.
\end{abstract}

Keywords: advanced energy systems, carbon nanotubes, smart materials

\section{Introduction}

Owing to the increasing demand for more efficient energy source and storage devices in our daily life (such as portable electronics and hybrid vehicles), increasing attention has been dedicated to producing energy storage flexible devices with improved cycle life- and charging/ discharging- rate.

The development of new electrochemical energy-related systems based on lithium-ion batteries (LIBs), ${ }^{1,2}$ microbial fuel cells (MFCs) ${ }^{3}$ and supercapacitors requires the production of sustainable electrode materials with high energy density, high power density, good cycling performance in association with simple and low cost processability, due to the successive insertion/ exclusion of ions during successive cycles. The use of polymeric structures with a stable skeleton and large conjugated structure represents an important strategy to preserve charge transfer mechanisms. ${ }^{1,2}$

Supercapacitors, also called electrochemical capacitors, present higher power- and energy- density. ${ }^{4-6}$

Typical supercapacitors (standard symmetrical assembly) are composed by two electrodes separated by a solid membrane. The energy storage is due to the formation of double layer and redox reactions in carbon derivatives and conducting polymer/ metal oxide, respectively. ${ }^{7-11}$

Non-Faradaic process dominates in the EDLC response and depends on specific surface area/ porosity of carbonbased materials. ${ }^{12-14}$ Carbon derivatives (such as carbon nanotubes, reduced graphene oxide - rGO and modified graphene - Claisen Graphene) $)^{15-19}$ have been considered as potential candidates for EDLC devices. Particularly, the chemical stability, strong mechanical resistance, superior electric conductivity, transparency in visible/ near infrared

\footnotetext{
* e-mail: helinando.oliveira@univasf.edu.br
}

region and flexibility play a pivotal role for application of carbon nanotubes in new types of electronic devices such as flexible devices, ${ }^{20}$ transparent electrode for dye-sensitized solar cell, ${ }^{21-23}$ anode for microbial fuel cell ${ }^{24}$ and so on.

On the other side, pseudocapacitors (conducting polymers and metal oxide nanoparticles) contribute to charge storage mechanisms due to their characteristic fast redox reaction (Faradaic process). Conducting polymers (such as polypyrrole - PPy) introduce important advantages relative to environmental stability, high conductivity, high chemical stability and processability. 4,12,25-27 In addition, the chemical synthesis of free-standing polypyrrole nanotubes provides a potential candidate for thermoelectric application ${ }^{28}$ and membrane for anode of microbial fuel cells. ${ }^{29}$

Based on these aspects, it has been reported the use of carbon-based materials in association with pseudocapacitors to achieve the desired performance for energy storage devices. ${ }^{30-33}$

In terms of pseudocapacitance, $\mathrm{MnO}_{2}$ presents an extraordinary theoretical specific capacitance of 1370 $\mathrm{F} / \mathrm{g},{ }^{31,34}$ which is associated with poor electrical properties (low conductivity).

To circumvent this limitation, the combination with conducting polymers offers an interesting alternative directed to the production of hybrid conducting polymer/ metal oxide composite with improved electrical/ electrochemical properties. ${ }^{31,35}$

The specific capacitance of polypyrrole nanotubes (reported by de Oliveira and de Oliveira) ${ }^{15}$ is in order of $47.83 \mathrm{~F} / \mathrm{g}$. The association of polypyrrole with modified graphene oxide returns capacitance in order of $277.8 \mathrm{~F} / \mathrm{g}{ }^{17}$ while association of GO and PPy provides capacitance in order of $289 \mathrm{~F} / \mathrm{g} .{ }^{25}$ The association of $\mathrm{MnO}_{2}$ and graphene results in a capacitance of $192 \mathrm{~F} / \mathrm{g}{ }^{19}$ while composites of $\mathrm{MnO}_{2} / \mathrm{GNS} / \mathrm{CNTs}$ returns a value in order of $132 \mathrm{~F} / \mathrm{g} .{ }^{19}$ 
The synthesis of polypyrrole on $\mathrm{MnO}_{2}$ surface results in a porous composite with increasing surface area and reduced deterioration degree of PPy during charging/ discharging process. ${ }^{34,36}$ The incorporation of carbon nanotubes improves the electrochemical- and mechanical- response of resulting highly flexible electrodes. ${ }^{31}$

Wang et al. ${ }^{37}$ reported the production of $\mathrm{MnO}_{2} / \mathrm{PPy}$ nanosheets (by chemical polymerization on carbon cloth) for symmetric supercapacitors. The combination of $\mathrm{Li}_{4} \mathrm{Ti}_{5} \mathrm{O}_{12}$ nanowire with MWCNTs deposited on carbon cloth and copper-nickel oxide nanostructures ${ }^{38}$ represent other interesting strategy in the direction to develop 3-d arrays with superior volumetric energy storage capabilitiy ${ }^{39} \mathrm{Li}$ et al. ${ }^{40}$ reported the combination of ferroferric oxide-carbon $\left(\mathrm{Fe}_{3} \mathrm{O}_{4}-\mathrm{C}\right)$ nanorod array as a convenient strategy for improvement in cyclability of electrodes. Alternatively, anodes based on core-shell structures such as $\mathrm{TiO}_{2}-\mathrm{MnO}_{2}{ }^{41}$ circumvents the typical low cyclability of individual components. As we can see, the association of components (carbon nanotubes, polypyrrole and $\mathrm{MnO}_{2}$ ) in hierarchical structures favors important applications due to the ion diffusion distance and available surface area for ionic reaction.

In this work, we have chemically synthesized dual core-shell organic-inorganic devices for application as supercapacitor electrodes. Corresponding systems (reported in the literature) ${ }^{42,43}$ were typically synthesized by electropolymerization. The relative concentration of carbon nanotubes in composites was varied in order to establish the best ratio of EDLC/ pseudocapacitance in hierarchical structures.

\section{Experimental Procedure}

Multi-walled carbon nanotubes (MWCNT), $\mathrm{KMnO}_{4}$, $\mathrm{MnSO}_{4}$, ammonium persulfate (APS), $\mathrm{HCl}$ and $\mathrm{KCl}$ were of analytical grade, produced by Aldrich and used as received, while pyrrole (Aldrich) was distilled before polymerization.

Dual core-shell coaxial composites were prepared according a two-step procedure: the synthesis of MWCNT@ $\mathrm{MnO}_{2}$ complex and the preparation of coaxial MWCNT@ $\mathrm{MnO}_{2} @ \mathrm{PPy}$.

\subsection{Synthesis of $\mathrm{MnO}_{2}$ nanorods $\left(\alpha-\mathrm{MnO}_{2}\right)$}

Nanorods of $\mathrm{MnO}_{2}$ were synthesized according procedure reported by Sen et al..44 $\mathrm{KMnO}_{4}$ aqueous solution $(0.1 \mathrm{M}$ in $10 \mathrm{~mL})$ was mixed with an aqueous solution of $\mathrm{MnSO}_{4}(0.15$ $\mathrm{M}$ in $10 \mathrm{~mL}$ ) and vigorously stirred for 6 hours. The resulting dark-brown precipitate was separated by centrifugation and dried at $100^{\circ} \mathrm{C}$.

\subsection{Synthesis of composite $M W C N T @ M n O_{2}$}

MWCNT@ $\mathrm{MnO}_{2}$ composite was synthesized according procedure reported by Li et al.:.$^{30} \mathrm{KMnO}_{4}(100 \mathrm{mg})$ was dispersed in milli-Q water $(50 \mathrm{~mL})$ at $80^{\circ} \mathrm{C}$ with variable amount of MWCNT viz. $0 \mathrm{mg}, 100 \mathrm{mg}, 200 \mathrm{mg}, 300 \mathrm{mg}$, $400 \mathrm{mg}$ and $500 \mathrm{mg}$. Resulting solution was acidified with aliquots of $\mathrm{HCl}(2 \mathrm{M})$ until reaches $\mathrm{pH} 3$. Continuous stirring for $10 \mathrm{~h}$ at ambient temperature completed the reaction. The resulting powder was rinsed with milli-Q water and filtered (under vacuum) followed by drying procedure (100 ${ }^{\circ} \mathrm{C}$ ). It is noteworthy that relative concentration of $\mathrm{MnO}_{2}$ in the composite remains fixed while relative concentration of MWCNT is varied, in order to identify the influence of carbon derivatives on overall response of device.

\subsection{Synthesis of dual core/ shell composite MWCNT@MnO_@polypyrrole}

According procedure described by Li et al., ${ }^{30}$ MWCNT@ $\mathrm{MnO}_{2}$ complex $(50 \mathrm{mg})$ was introduced in $30 \mathrm{~mL}$ of SDS aqueous solution $(5 \mathrm{mM})$. The resulting material was vigorously stirring stirred for 20 minutes. Pyrrole $(0.21$ $\mathrm{mL}$ ) was added to the final product, which was kept at $2{ }^{\circ} \mathrm{C}$ under stirring for 5 minutes. After this step, APS aqueous solution - $0.06 \mathrm{M}(50 \mathrm{~mL})$ was slowly dropwised into the previous solution (kept at $2{ }^{\circ} \mathrm{C}$ ) under continuous stirring for 2 hours. The resulting powder was filtered (under vacuum) and dried at $70{ }^{\circ} \mathrm{C}$ overnight. Resulting powder $(50 \mathrm{mg})$ was pressed in pellets of $13 \mathrm{~mm}$-diameter under $20 \mathrm{kN}$ and soaked into standard electrolyte $(\mathrm{KCl}$ aqueous solution - 1M) overnight for incorporation of electrolyte into composites and separator. For comparison, samples of PPy@ $\mathrm{MnO}_{2}$ were prepared considering the corresponding mass of $\mathrm{MnO}_{2}(50 \mathrm{mg})$.

\subsection{Characterization techniques}

The morphology of nanostructures was explored from images of scanning electron microscopy (SEM) using a Quanta 200 FEG microscopy (voltage of $20 \mathrm{kV}$ ) and transmission electron microscopy (TEM) by TEM FEI Tecnai $20-200 \mathrm{kV}$. Fourier Transform Infrared (FTIR) spectrum of material was performed in an IR-Prestige-21 FTIR Shimadzu.

The electrochemical responses (cyclic voltammetry - CV), impedance spectrum and galvanostatic charge-discharge cycling (GCD) curves were performed by potentiostat/ galvanostat Autolab PGSTAT 302N. DC conductivity of composite was determined using a Keythley 2002 multimeter connected to a 12962 Solartron Sample Holder.

Specific surface area of devices was performed according Brunauer-Emmett-Teller (BET) technique using a Micromeritics ASAP 2420 surface area analyzer.

Symmetric assembly of pellets of composites separated by commercial ion exchange membrane (Celgard) was introduced between two electrodes of 12962 Solartron Sample Holder, while the electrochemical characterization was provided by potentiostat. GCD curves were performed with charging-discharging curves acquired at $6 \mathrm{~mA} /-6 \mathrm{~mA}$, 
respectively. Specific capacitance (C) in a symmetrical twoelectrodes is given by Eq. $1 .^{45}$

$$
C=\frac{4 I}{m\left(\frac{d V}{d t}\right)}
$$

where $\mathrm{m}$ represents the total mass of electrodes and $\mathrm{dV} /$ $\mathrm{dt}$ is slope of discharge curve established at fixed current.

\section{Results}

The morphology of resulting material is shown in the TEM images of Figure 1. Nanorods of $\mathrm{MnO}_{2}((69.00 \pm 4.64)$ $\mathrm{nm}$ of length - as shown in the Figure 1a) resulted from synthesis described in the Section 2.1.

Composites of MWCNT@ $\mathrm{MnO}_{2}$ (Figure 1b) are characterized by tubular morphology. The increase in the diameter of nanotubes can be attributed to the covering of $\mathrm{MnO}_{2}$ on MWCNT surface.

TEM image of composite MWCNT@ $\mathrm{MnO}_{2} @$ PPy (Figure 1c) shows partial covering of PPy on hybrid structure (polypyrrole grains are shown in the Figure 1d). The polymerization of PPy on the surface of MWCNT@ $\mathrm{MnO}_{2}$ complex affects the fiber diameter, as clearly indicated in the SEM images - by comparison with Figure 2a (MWCNT)/ Figure2b (MWCNT@ $\mathrm{MnO}_{2}$ structure) with Figure 2c / Figure2d (MWCNT@MnO,@ PPy). The identification of components is shown in the EDS overlaid image (Figure 2e) with corresponding distribution of $\mathrm{O}$ and $\mathrm{Mn}$ (Figure $2 \mathrm{f}$ and Figure $2 \mathrm{~g}$, respectively).

The diameter of pristine carbon nanotubes $(6-9 \mathrm{~nm}$, length $5 \mathrm{~mm}$ and BET of $253.0 \mathrm{~m}^{2} / \mathrm{g}$, according supplier) increases to $(47.05 \pm 5.12) \mathrm{nm}$ after incorporation of $\mathrm{MnO}_{2}$ (composite MWCNT@ $\mathrm{MnO}_{2}$ ) and to (143.15 \pm 6.59 )nm with successive covering of polypyrrole (MWCNT@MnO $@$ PPy).

The measured value BET surface area of composite MWCNT@MnO @ @Py was in order of 82.22 m²/g, as a consequence of covering of conducting polymer on coaxial structure of MWCNT@ $\mathrm{MnO}_{2}$ (corresponding surface area of $\alpha-\mathrm{MnO}_{2}$ is in order of $78.40 \mathrm{~m}^{2} / \mathrm{g}$ ).

\subsection{Structure analysis}

FTIR spectra of $\alpha-\mathrm{MnO}_{2}$, polypyrrole, MWCNT@ $\mathrm{MnO}_{2}$ and $\mathrm{MWCNT} @ \mathrm{MnO}_{2} @$ polypyrrole are shown in the Figure 3. Bands at 3434 and $1630 \mathrm{~cm}^{-1}$ are attributed to $\mathrm{O}-\mathrm{H}$ stretching. Mn-O vibration modes are identified from broad band between $500 \mathrm{~cm}^{-1}$ and $800 \mathrm{~cm}^{-1}{ }^{44,46}$

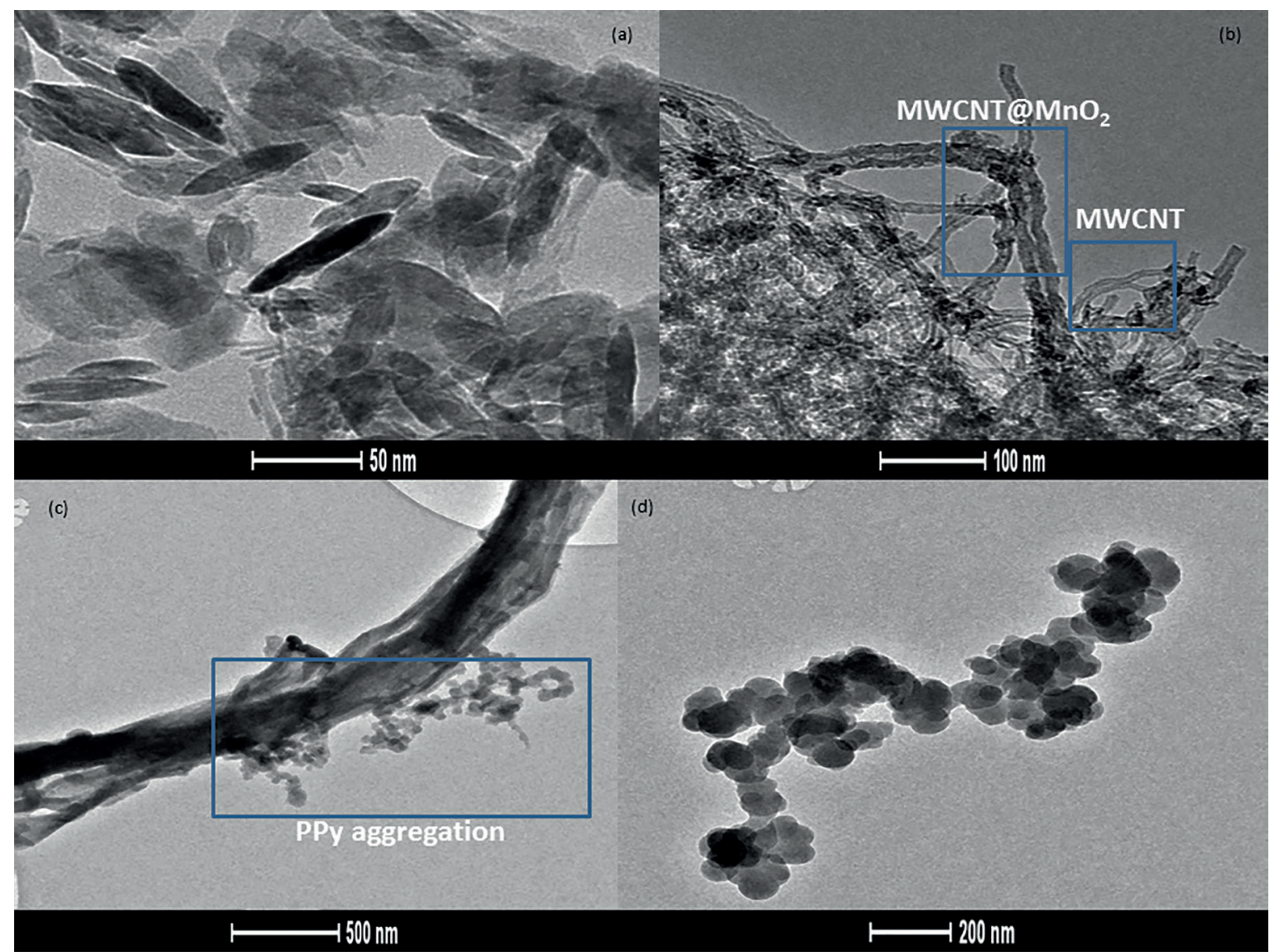

Figure 1: TEM images of (a) $\mathrm{MnO}_{2}$ nanorods - scale bar of $50 \mathrm{~nm}$, (b) MWCNT (100 mg)@ $\mathrm{MnO}_{2}-$ scale bar of $100 \mathrm{~nm}$, (c) MWCNT (100 mg)@MnO @PPy - scale bar of 500 nm and (d) polypyrrole aggregates - scale bar of $200 \mathrm{~nm}$. 

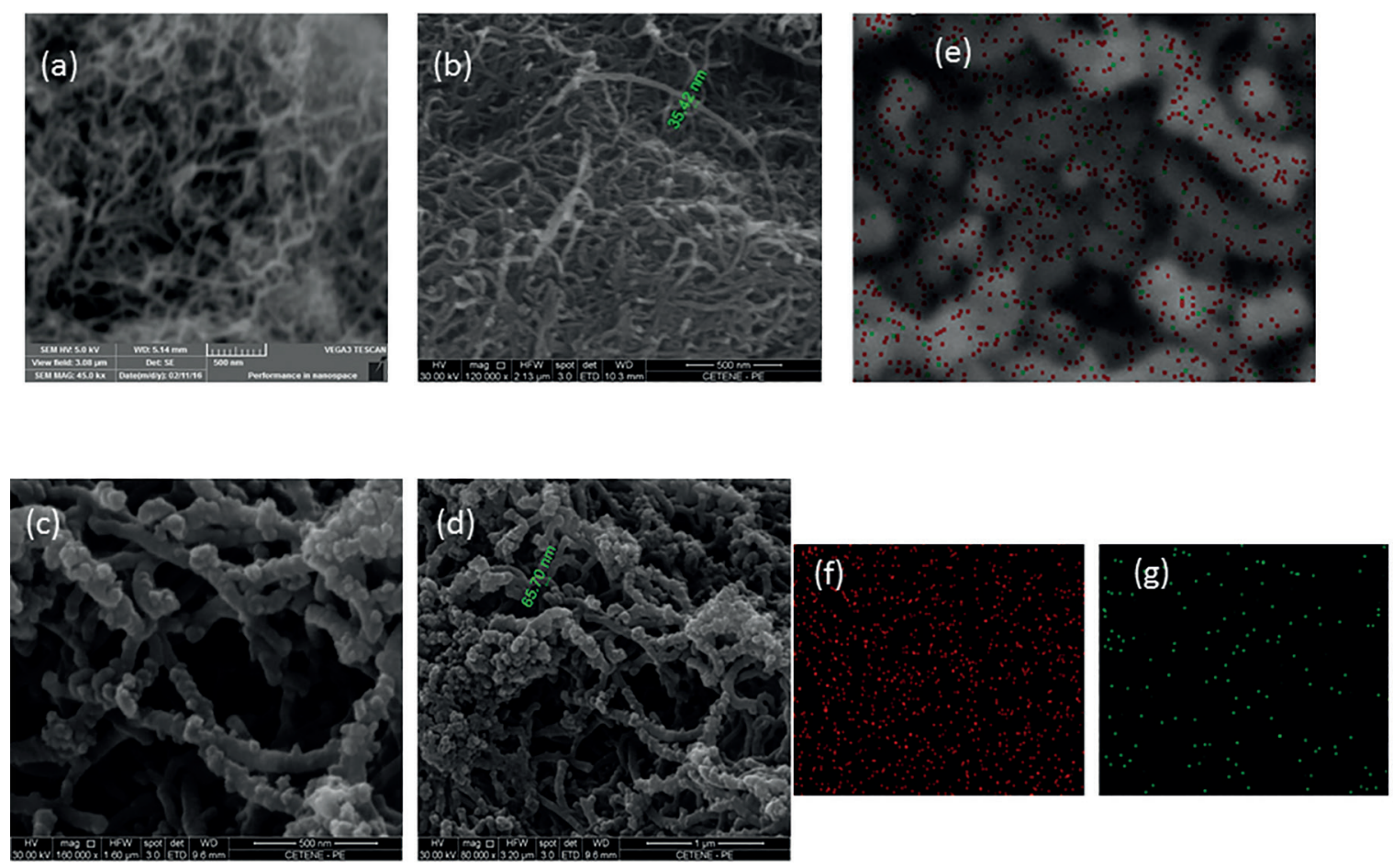

Figure 2: SEM images of MWCNT (a), MWCNT(500 mg)@MnO 2 complex (b), MWCNT (500 mg)@MnO_@PPy composite (c and d), overlaid EDX image of MWCNT@ $\mathrm{MnO}_{2} @$ PPy composite (500 mg) (e) and identification of oxygen (f) and Mn (g) - values indicated in the Figs. $2 \mathrm{~b}$ and $2 \mathrm{~d}$ correspond to measured diameter of indicated fiber.
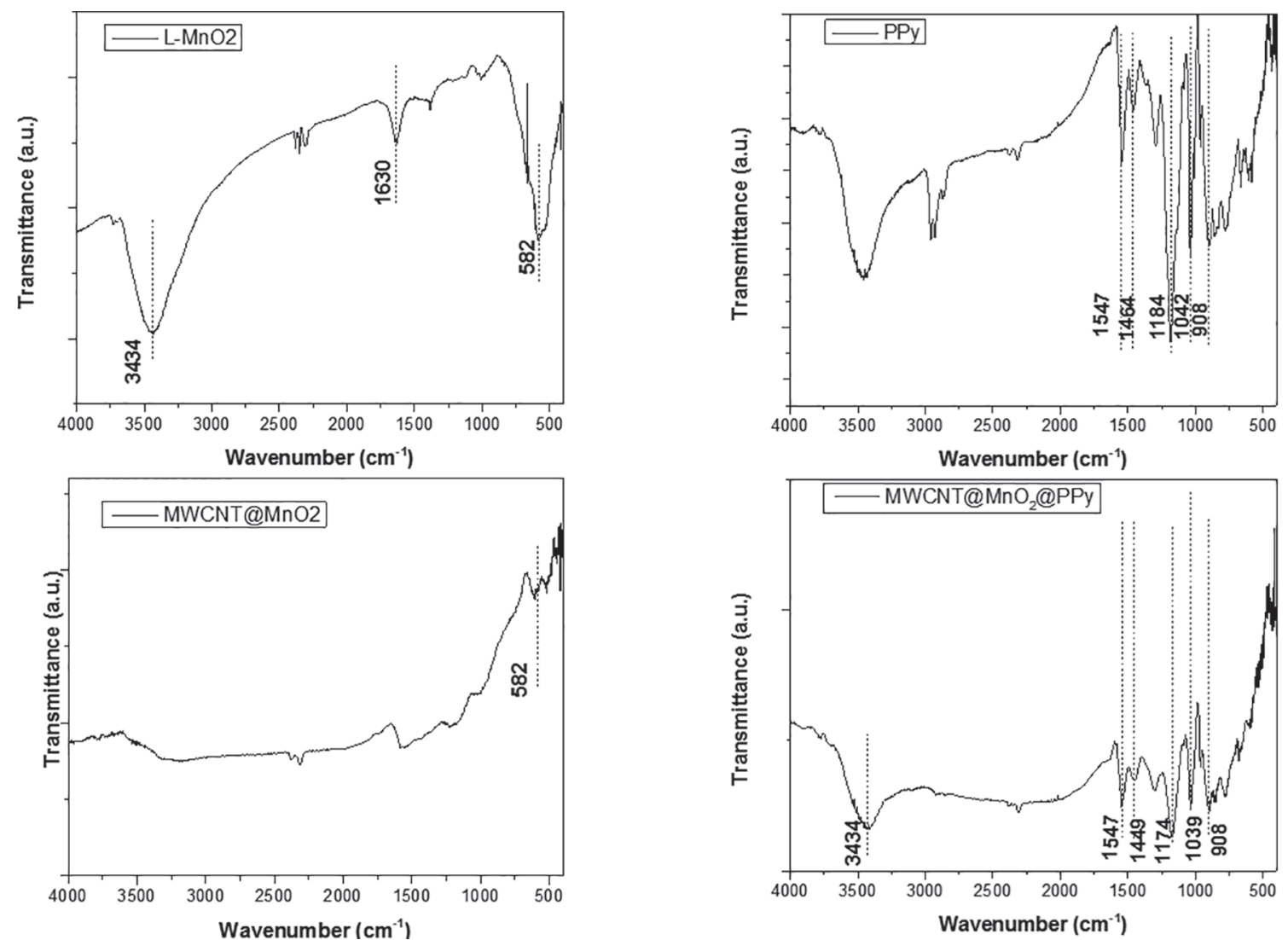

Figure 3: FTIR spectrum of $\alpha-\mathrm{MnO}_{2}$, polypyrrole, $\mathrm{MWCNT} @ \mathrm{MnO}_{2}$ and $\mathrm{MWCNT} @ \mathrm{MnO}_{2} @ \mathrm{PPy}$ coaxial nanostructures. 
Characteristic bands of polypyrrole are identified at 1547 and $1464 \mathrm{~cm}^{-1}\left(\mathrm{C}=\mathrm{C}\right.$ and $\mathrm{C}-\mathrm{C}$ vibrations), $1184 \mathrm{~cm}^{-1}$ (C-C breathing vibration) ${ }^{47}$ and $908 \mathrm{~cm}^{-1}$ (out of plane vibration of $=\mathrm{C}-\mathrm{H}){ }^{48}$ The peak at $1042 \mathrm{~cm}^{-1}$ is assigned to $\mathrm{C}-\mathrm{H}$ in-plane vibration bands of the pyrrole ring. ${ }^{17}$

The coaxial nanostructure (MWCNT@MnO $@$ PPy) presents band at $3434 \mathrm{~cm}^{-1}\left(\mathrm{MnO}_{2}\right)$ while bands at 1547 , $1449,1174,1039$ and $908 \mathrm{~cm}^{-1}$ are assigned to the presence of polypyrrole in coaxial composite, in analogy with previously reported peaks. It is noteworthy that some of these peaks are shifted to lower energies, as result of interaction between polypyrrole/MWCNT and polypyrrole/ $\mathrm{MnO}_{2}$.

\subsection{Electrical and electrochemical characterization of composites MWCNT@ $\mathrm{MnO}_{2} @$ Polypyrrole}

The conductivity of pellets prepared at different relative concentration of MWCNT@ $\mathrm{MnO}_{2}$ is strongly affected by increase in the relative concentration of $\mathrm{MWCNT} / \mathrm{MnO}_{2}$ complex in the resulting MWCNT@ $\mathrm{MnO}_{2} @$ PPy composite, as shown in the Figure 4.

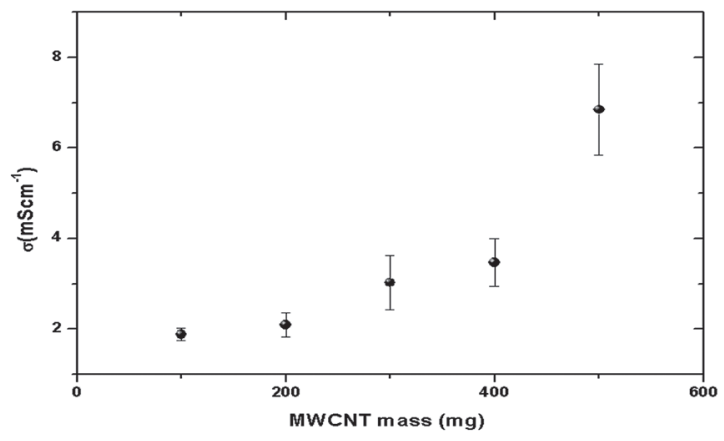

Figure 4: DC conductivity of coaxial composites of MWCNT@ $\mathrm{MnO}_{2} @$ PPy prepared using increasing rate of $\mathrm{MWCNT} / \mathrm{MnO}_{2}$.

The progressive incorporation of MWCNT on coaxial nanostructures improves the conductivity of resulting composite, with direct implication on reduction of IR drop during charge/ discharge procedure.

Corresponding electrochemical impedance spectrum of MWCNT@MnO_@PPy (shown in the Nyquist plots of Figure 5 a) is composed by two specific regions viz. a semicircle (which corresponds to faradaic reactions) and a straight line due to the interfacial effects at low frequency excitation. The results reveal that incorporation of carbon nanotubes (above $100 \mathrm{mg}$ ) affects the slope of linear branch (low frequency) and the diameter of characteristic semicircle.

The complete response in the Nyquist diagram has been simulated by corresponding equivalent circuit (shown in the inset of Figure 5a) obtained by association of bulk solution resistance $\left(R_{s}\right)$, charge transfer resistance $\left(R_{c t}\right)$, a constant phase element (CPE) that characterizes pseudocapacitance
$\left(\mathrm{C}_{\mathrm{p}}\right)$ and a double layer capacitor $\left(\mathrm{C}_{\mathrm{dl}}\right)$. Overlaid lines on impedance spectrum of Figure 5a represent the best fitting from equivalent circuit (modified Randles circuit). From corresponding parameters (returned from fitting of curves), $\mathrm{C}_{\mathrm{dl}}$ presented an interesting behavior in terms of dependence with MWCNT concentration. As shown in the inset of Figure $5 \mathrm{a}$, the maximum in the $\mathrm{C}_{\mathrm{dl}}$ is verified for samples prepared with $300 \mathrm{mg}$ of MWCNT, indicating that morphology of resulting sample prepared at specific concentration favors the charge accumulation at the interface carbon derivative/ electrolyte. The corresponding $\mathrm{C}-\mathrm{V}$ curves profile is shown in the Figure 5b, which considers samples prepared using 500 $\mathrm{mg}$ of MWCNT. The corresponding values of capacitance (shown in the legend of Figure 5b) varies inversely with scan rate of voltage, as expected - corresponding curves are shown in the Figure 5c. Cycling performance is indicated in the Figure $5 \mathrm{~d}$.

GCD curves (shown in the Figure 6a) indicated that capacitance in order of $76.67 \mathrm{~F} / \mathrm{g}$ is obtained for composites of $\mathrm{MnO}_{2} @ \mathrm{PPy}$.

The incorporation of MWCNT/ metal oxide as support for polymer growth improved the electrochemical response of material. The inclusion of MWCNT (100 mg of carbon nanotubes during preparation of $\mathrm{MWCNT} @ \mathrm{MnO}_{2}$ ) results in a capacitance of $91.25 \mathrm{~F} / \mathrm{g}$. while $200 \mathrm{mg}$ of MWCNT improves the specific capacitance to value in order of $133.25 \mathrm{~F} / \mathrm{g}$.

Specific capacitance reaches a maximum $(272.72 \mathrm{~F} / \mathrm{g})$ for samples prepared using $300 \mathrm{mg}$ of MWCNT (as shown in the Figure $6 \mathrm{~b}$ ). The corresponding cycling performance test returned a value of capacitance retention in order of $60 \%$ after 300 cycles of charge/discharge for this sample (as shown in the Figure 5d).

Progressive incorporation of MWCNT (above 300 $\mathrm{mg})$ reduced the specific capacitance $(211.05 \mathrm{~F} / \mathrm{g}-400 \mathrm{mg}$ of MWCNT and $139.77 \mathrm{~F} / \mathrm{g}$ - $500 \mathrm{mg}$ of MWCNT). The dependence of specific capacitance of devices with amount of MWCNT is in agreement with corresponding dependence of double layer capacitance (inset of Figure 5a), confirming that electrochemical performance of device depends on relative concentration of carbon nanotubes.

In spite of continuous increase in the conductivity level in response of progressive incorporation of MWCNT in complex, the charge accumulation on double layer reaches an optimal condition at intermediate concentration of MWCNT (300 mg).

As consequence, the best condition for application of composites as supercapacitors was dominated by performance of EDLC in complex.

\section{Conclusions}

The improved electrical conductivity of electrodes and available surface area for charge accumulation in composites 
(a)
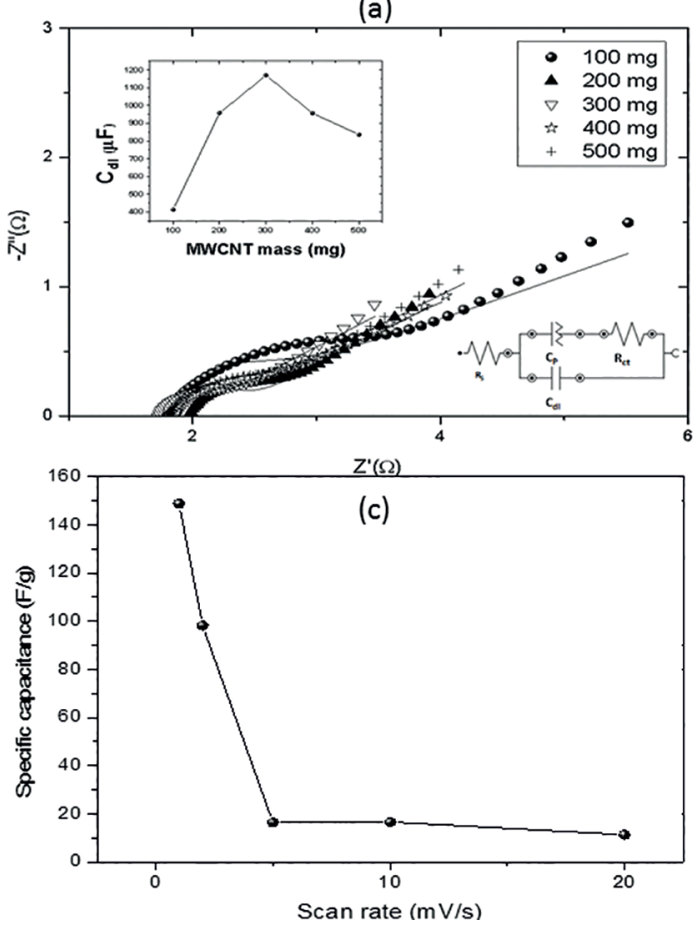

(b)
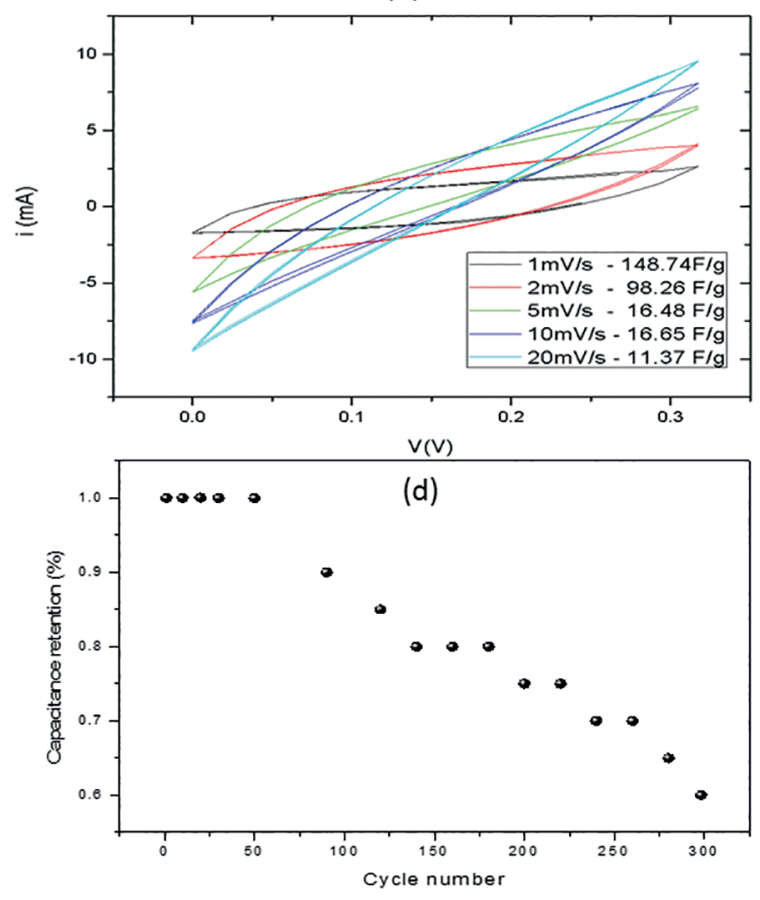

Figure 5: (a) Nyquist plots of supercapacitors prepared using increasing rate of $\mathrm{MWCNT} / \mathrm{MnO}_{2}$. In the inset are shown the corresponding equivalent circuit (right) and dependence of double layer capacitance $\left(\mathrm{C}_{\mathrm{dl}}\right)$ with amount of MWCNT and (b) C-V curves of coaxial composite MWCNT (500 mg)@MnO @PPy and corresponding calculated capacitance, (c) corresponding dependence of capacitance vs. scan rate and (d) cycling performance of supercapacitor.

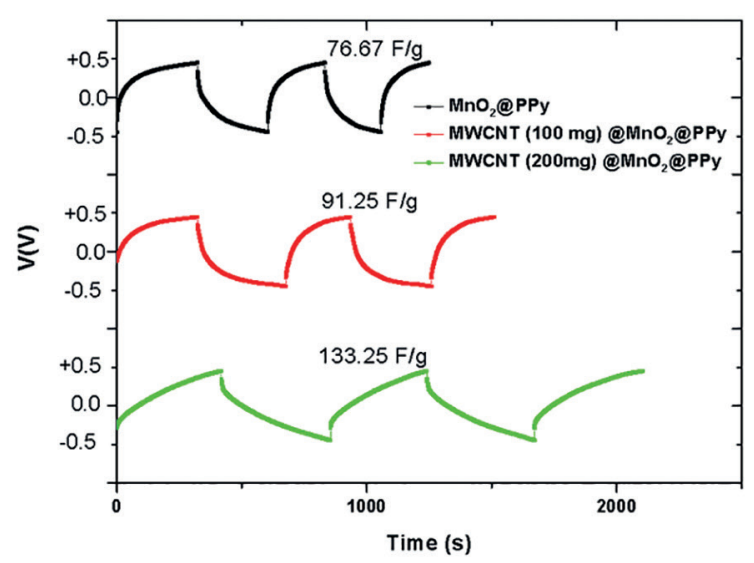

(a)

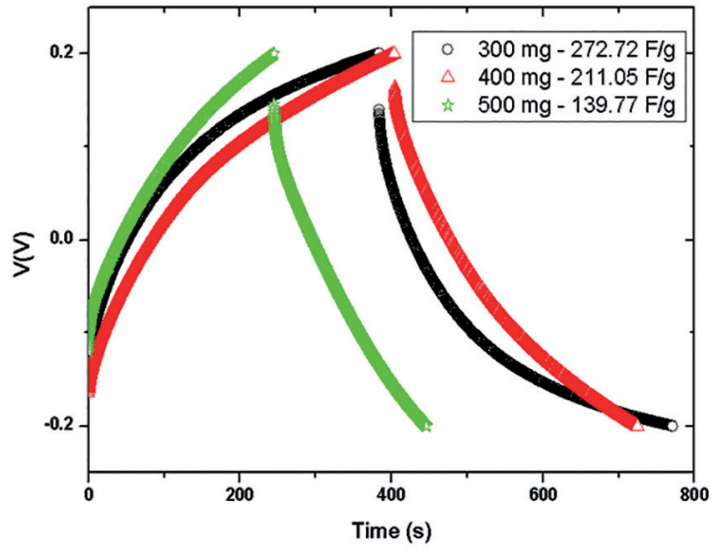

(b)

Figure 6: (a) GCD curves of coaxial composite MWCNT (0 mg, 100 mg, 200 mg)@MnO_@PPy and (b) GCD curves of coaxial composite MWCNT (300 mg, 400 mg and 500 mg)@MnO @PPy.

of MWCNT@MnO $@$ PPy play a pivotal role to achieve the adequate condition for optimal performance of corresponding electrochemical device.

The relative concentration of MWCNT in coaxial MWCNT@ $\mathrm{MnO}_{2}$ complex covered by polypyrrole affects charge transfer mechanisms and dielectric response of resulting composite.
The dependence of double layer capacitance with relative concentration of carbon nanotubes in the composite is in agreement with response of specific capacitance of resulting devices, which reaches optimal value in order of $272.72 \mathrm{~F} / \mathrm{g}$, characterizing an adequate condition for device implementation. 


\section{Acknowledgement}

The authors wish to thank FACEPE, FINEP, CNPq, FAPESB, and CAPES for financial support.

\section{References}

1. Wu J, Rui X, Long G, Chen W, Yan Q, Zhang Q. Pushing Up Lithium Storage through Nanostructured Polyazaacene Analogues as Anode. Angewandte Chemie International Edition. 2015;54(25):7354-7358.

2. Wu J, Rui X, Wang C, Pei WB, Lau R, Yan Q, et al. Nanostructured Conjugated Ladder Polymers for Stable and Fast Lithium Storage Anodes with High-Capacity. Advanced Energy Materials. 2015;5(9):1402189.

3. Xie J, Zhao CE, Lin ZQ, Gu PY, Zhang Q. Nanostructured Conjugated Polymers for Energy-Related Applications beyond Solar Cells. Chemistry - An Asian Journal. 2016;11(10):1489-511.

4. Chee WK, Lim HN, Huang NM. Electrochemical properties of free-standing polypyrrole/graphene oxide/zinc oxide flexible supercapacitor. International Journal of Energy Research. 2015;39(1):111-119.

5. Zhang Q, Rong J, Wei B. A divided potential driving self-discharge process for single-walled carbon nanotube based supercapacitors. RSC Advances. 2011;1(6):989-994.

6. Brezesinski T, Wang J, Tolbert SH, Dunn B. Next generation pseudocapacitor materials from sol-gel derived transition metal oxides. Journal of Sol-Gel Science and Technology. 2011;57(3):330-335.

7. Moon JS, Kim H, Lee DC, Lee JT, Yushina G. Increasing Capacitance of Zeolite-Templated Carbons in Electric Double Layer Capacitors. Journal of The Electrochemical Society. 2015;162(5):A5070-A5076.

8. Lee YH, Chang KH, Hu CC. Differentiate the pseudocapacitance and double-layer capacitance contributions for nitrogen-doped reduced graphene oxide in acidic and alkaline electrolytes. Journal of Power Sources. 2013;227:300-308.

9. Brezesinski K, Wang J, Haetge J, Reitz C, Steinmueller SO, Tolbert $\mathrm{SH}$, et al. Pseudocapacitive contributions to charge storage in highly ordered mesoporous group $\mathrm{V}$ transition metal oxides with iso-oriented layered nanocrystalline domains. Journal of the American Chemical Society. 2010;132(20):6982-6990.

10. Zhou M, Glushenkov AM, Kartachova O, Li Y, Chen Y. Titanium Dioxide Nanotube Films for Electrochemical Supercapacitors: Biocompatibility and Operation in an Electrolyte Based on a Physiological Fluid. Jounal of the Electrochemical Society. 2015;162(5):A5065-A5069.

11. Dubal DP, Lee SH, Kim JG, Kim WB, Lokhande CD. Porous polypyrrole clusters prepared by electropolymerization for a high performance supercapacitor. Journal of Materials Chemistry. 2012;22(7):3044-3052

12. Bleda-Martínez MJ, Maciá-Agullá JA, Lozano-Castelló D, Morallón E, Cazorla-Amorós D, Linares-Solano A. Role of surface chemistry on electric double layer capacitance of carbon materials. Carbon. 2005;43(13):2677-2684.
13. Chen H, Wang H, Yang L, Xiao Y, Zheng M, Liu Y, et al. High Specific Surface Area Rice Hull Based Porous Carbon Prepared for EDLCs. International Journal of Electrochemical Science. 2012;7(6):4889-4897.

14. Wei L, Yushin G. Nanostructured activated carbons from natural precursors for electrical double layer capacitors. Nano Energy. 2012;1(4):552-565.

15. Oliveira AHP, Oliveira HP. Carbon nanotube/ polypyrrole nanofibers core-shell composites decorated with titanium dioxide nanoparticles for supercapacitor electrodes. Journal of Power Sources. 2014;268:45-49.

16. Dhibar S, Das CK. Silver Nanoparticles Decorated Polyaniline/ Multiwalled Carbon Nanotubes Nanocomposite for HighPerformance Supercapacitor Electrode. Industrial \& Engineering Chemistry Research. 2014;53(9):3495-3508.

17. Oliveira HP, Sydlik SA, Swager TM. Supercapacitors from Free-Standing Polypyrrole/Graphene Nanocomposites. Journal of Physical Chemistry C. 2013;117(20):10270-10276.

18. Yan J, Liu J, Fan Z, Wei T, Zhang L. High-performance supercapacitor electrodes based on highly corrugated graphene sheets. Carbon. 2012;50(6):2179-2188.

19. Liu Y, He D, Duan J, Wang Y, Li S. Synthesis of MnO2/ graphene/carbon nanotube nanostructured ternary composite for supercapacitor electrodes with high rate capability. Materials Chemistry and Physics. 2014;147(1-2):141-146.

20. Zhao W, Fan S, Xiao N, Liu D, Tay YY, Yu C, et al. Flexible carbon nanotube papers with improved thermoelectric properties. Energy \& Environmental Science. 2012;5(1):5364-5369.

21. Kyaw AKK, Tantang H, Wu T, Ke L, Peh C, Huang ZH, et al. Dye-sensitized solar cell with a titanium-oxide-modified carbon nanotube transparent electrode. Applied Physics Letters. 2011;99:021107.

22. Kyaw AKK, Tantang H, Wu T, Ke L, Wei J, Demir HV, et al. Dye-sensitized solar cell with a pair of carbon-based electrodes. Journal of Physics D: Applied Physics. 2012;45:65103.

23. Tantang H, Kyaw AKK, Zhao Y, Chan-Park MB, Tok AI, Hu Z, et al. Nitrogen-doped carbon nanotube-based bilayer thin film as transparent counter electrode for dye-sensitized solar cells (DSSCs). Chemistry - An Asian Journal. 2012;7(3):541-545.

24. Zhao CE, Wu J, Ding Y, Wang VB, Zhang Y, Kjelleberg S, et al. Hybrid Conducting Biofilm with Built-in Bacteria for High-Performance Microbial Fuel Cells. ChemElectroChem. 2015;2(5):654-658.

25. Chang HH, Chang CK, Tsai YC, Liao CS. Electrochemically synthesized graphene/polypyrrole composites and their use in supercapacitor. Carbon. 2012;50(6):2331-2336.

26. Shi Y, Pan L, Liu B, Wang Y, Cui Y, Bao Z, et al. Nanostructured conductive polypyrrole hydrogels as high-performance, flexible supercapacitor electrodes. Journal of Materials Chemistry A. 2014;2(17):6086-6091.

27. Bora C, Dolui SK. Fabrication of polypyrrole/graphene oxide nanocomposites by liquid/liquid interfacial polymerization and evaluation of their optical, electrical and electrochemical properties. Polymer. 2012;53(4):923-932. 
28. Wu J, Sun Y, Pei WB, Huang L, Xu W, Zhang Q. Polypyrrole Nanotube Film for Flexible Thermoelectric Application. Synthetic Metals. 2014;196:173-177.

29. Zhao CE, Wu J, Kjelleberg S, Loo JSC, Zhang Q. Employing a Flexible and Low-Cost Polypyrrole Nanotube Membrane as an Anode to Enhance Current Generation in Microbial Fuel Cells. Small. 2015;11(28):3440-3443.

30. Li J, Zou M, Zhao Y, Lin Y, Lai H, Guan L, et al. Coaxial MWNTs@MnO2 confined in conducting PPy for kinetically efficient and long-term lithium ion storage. Electrochimica Acta. 2013;111:165-171.

31. Yuan L, Lu XH, Xiao X, Zhai T, Dai J, Zhang F, et al. Flexible Solid-State Supercapacitors Based on Carbon Nanoparticles/ MnO2 Nanorods Hybrid Structure. ACS Nano. 2012;6(1):656-661.

32. Li P, Shi E, Yang Y, Shang Y, Peng Q, Wu S, et al. Carbon nanotube-polypyrrole core-shell sponge and its application as highly compressible supercapacitor electrode. Nano Research. 2014;7(2):209-218

33. Zhou Y, Qin ZY, Li L, Zhang Y, Wei YL, Wang LF, et al. Polyaniline/multi-walled carbon nanotube composites with core-shell structures as supercapacitor electrode materials. Electrochimica Acta. 2010;55(12):3904-3908.

34. Tao J, Liu N, Ma W, Ding L, Li L, Su J, et al. Solid-State High Performance Flexible Supercapacitors Based on PolypyrroleMnO2-Carbon Fiber Hybrid Structure. Scientific Reports. 2013;3:2286.

35. Yuan L, Wan C, Zhao L. Facial In-situ Synthesis of MnO2/ PPy Composite for Supercapacitor. International Journal of Electrochemical Science. 2015;(10):9456-9465.

36. Cheng Q, Tang J, Ma J, Zhang H, Shinya N, Qin L-C. Graphene and nanostructured $\mathrm{MnO} 2$ composite electrodes for supercapacitors. Carbon. 2011; 49(9):2917-2925.

37. Wang C, Zhan Y, Wu L, Li Y, Liu J. High-voltage and high-rate symmetric supercapacitor based on $\mathrm{MnO} 2$-polypyrrole hybrid nanofilm. Nanotechnology. 2014; 25(30): 305401.

38. Li R, Lin Z, Ba X, Li Y, Ding R, Liu, J. Integrated copper-nickel oxide mesoporous nanowire arrays for high energy density aqueous asymmetric supercapacitors. Nanoscale Horizons. 2016;1(2):150-155.
39. Zuo W, Wang C, Li Y, Liu J. Directly Grown Nanostructured Electrodes for High Volumetric Energy Density Binder-Free Hybrid Supercapacitors: A Case Study of CNTs// $\mathrm{Li}_{4} \mathrm{Ti}_{5} \mathrm{O}_{12}$. Scientific Reports. 2015;5:7780.

40. Li R, Wang Y, Zhou C, Wang C, Ba X, Li Y, et al. CarbonStabilized High-Capacity Ferroferric Oxide Nanorod Array for Flexible Solid-State Alkaline Battery-Supercapacitor Hybrid Device with High Environmental Suitability. Advanced Functional Materials. 2015;25(33):5384-5394.

41. Wang C, Wu L, Wang H, Zuo W, Li Y, Liu J. Fabrication and Shell Optimization of Synergistic $\mathrm{TiO}_{2}-\mathrm{MoO}_{3}$ Core-Shell Nanowire Array Anode for High Energy and Power Density Lithium-Ion Batteries. Advanced Functional Materials. 2015;25(23):3524-3533

42. Li P, Yang Y, Shi E, Shen Q, Shang Y, Wu S, et al. CoreDouble-Shell, Carbon Nanotube@Polypyrrole@MnO, sponge as freestanding, compressible supercapacitor electrode. ACS Applied Materials \& Interfaces. 2014;6(7):5228-5234.

43. Zhou J, Zhao H, Mu X, Chen J, Zhang P, Wang Y, et al Importance of polypyrrole in constructing 3D hierarchical carbon nanotube@MnO2 perfect core-shell nanostructures for high-performance flexible supercapacitors. Nanoscale. 2015;7(35):14697-14706.

44. Sen P, De A, Chowdhury AD, Bandyopadhyay SK, Agnihotri $\mathrm{N}$, Mukherjee M. Conducting polymer based manganese dioxide nanopacomposite as supercapacitor. Electrochimica Acta. 2013;108:265-273

45. Stoller MD, Ruoff RS. Best practice methods for determining an electrode material's performance for ultracapacitors. Energy \& Environmental Science. 2010;3(9):1294-1301.

46. Dong ZH, Wei YL, Shi W, Zhang GA. Characterisation of doped polypyrrole/manganese oxide nanocomposite for supercapacitor electrodes. Materials Chemistry and Physics. 2011;131(1-2):529-534.

47. Zhang AQ, Xiao YH, Lu LZ, Wang LZ, Li F. Polypyrrole/ $\mathrm{MnO}_{2}$ composites and their enhanced electrochemical capacitance. Journal of Applied Polymer Science. 2013;128(3):1327-1331.

48. Lei W, He P, Zhang S, Dong F, Ma Y. One-step triple-phase interfacial synthesis of polyaniline-coated polypyrrole composite and its application as electrode materials for supercapacitors. Journal of Power Sources. 2014;266:347-352. 